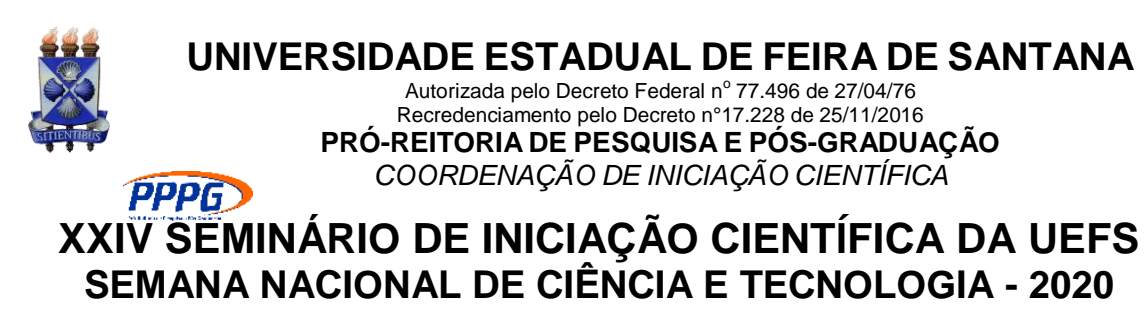

\title{
CONFLITOS E DILEMAS ÉTICOS VIVENCIADOS PELOS ENFERMEIROS NA TOMADA DE DECISÃO PARA O GERENCIAMENTO DO CENTRO CIRÚRGICO
}

\author{
Déborah de Oliveira Souza ${ }^{1}$; Elaine Guedes Fontoura ${ }^{2}$ \\ 1. Bolsista PIBIC/CNPq, Graduanda em Enfermagem, Universidade Estadual de Feira de Santana, e-mail: \\ debsouza15@outlook.com \\ 2. Orientadora, Departamento de Saúde, Universidade Estadual de Feira de Santana, e-mail: \\ elaineguedesfont@uol.com.br; egfontoura@uefs.br
}

PALAVRAS-CHAVE: Tomada de decisões; Gerenciamento; Centro Cirúrgico.

\section{INTRODUÇÃO}

O Código de Ética dos Profissionais de Enfermagem (CEPE) é um guia de orientação a conduta legal dos enfermeiros CONSELHO FEDERAL DE ENFERMAGEM, 2017 (COFEN). Estes, têm o papel de administrar e/ou gerenciar a equipe multidisciplinar no trabalho em enfermagem (TREVISO et al., 2017). A administração do cuidado compreende a conexão entre o trabalho gerencial e assistencial. Ao primeiro termo, refere-se ao planejamento á execução do serviço, a articulação da equipe, os instrumentos técnicos, a supervisão do desempenho, demanda de materiais, educação permanente, dentre outros aspectos que propõem as condições adequadas para uma melhor assistência (COPELLI et al., 2017).

O Centro Cirúrgico (CC) é um local na unidade hospitalar que tem por finalidade fazer cirurgias de pequena, média e alta complexidade. Em que, o cenário que o compõe é multiprofissional, o que requer que cada membro da equipe exerça o papel que lhe compete a luz da bioética, respeitando a individualidade e espaço dos colegas simultâneo a articulação de suas ações (SILVA et al., 2017), para que ocorra a interação da equipe em favor de um objetivo comum, atendendo assim o paciente de forma integral.

Porém, quando as ações não procedem dessa forma, os conflitos surgem devido as divergências de opiniões e interesses, diante da execução do trabalho da equipe do CC, que nem sempre é realizado de maneira segura e de acordo aos conhecimentos técnicoscientíficos de cada profissional, visando o bem estar do assistido, com respeito a autonomia dos colegas e atenção integral ao paciente (ASSIS et al., 2017).

Os dilemas éticos, se apresentam em situações em que existe a possibilidade de escolha e exige que esta aconteça, porém as opções são desagradáveis (OLIVEIRA; SANTA ROSA, 2016), ou seja, são alternativas consideradas excludentes e contraditórias, dessa forma, ocorre uma colisão de valores que não seguem regras (OLIVEIRA; SANTA ROSA, 2015).

Diante do exposto, a tomada de decisões é papel fundamental a conduta do enfermeiro, sendo que esta deve respeitar o paciente na sua integralidade, inclusive suas crenças e princípios, levando em consideração as teorias éticas, além do respeito aos profissionais que compõe a equipe (OLIVEIRA; SANTA ROSA, 2014). 
A motivação para realizar esta pesquisa foi participar do Núcleo Interdisciplinar de Pesquisas e Estudos em Saúde (NIPES) da Universidade Estadual de Feira de Santana (UEFS), em que emergiu o questionamento: Como o enfermeiro vivencia os conflitos e dilemas éticos na tomada de decisão para o gerenciamento no CC?, uma vez que a equipe é constituída por diferentes pessoas, com conhecimentos técnicos-científicos distintos e que existem divergências de princípios, valores, crenças e opiniões.

Assim, o estudo tem como objetivo de conhecer e descrever os conflitos e dilemas éticos vivenciados pelos enfermeiros na tomada de decisão para o gerenciamento no CC e compreender as estratégias de enfrentamentos adotadas pelos enfermeiros frente a estes.

\section{MATERIAL E MÉTODOS}

O presente estudo está contido no projeto intitulado "Conflitos e Dilemas Éticos Vividos no Cuidado da Equipe de Saúde no Contexto Hospitalar", que foi submetido ao Comitê de Ética em Pesquisa da UEFS, CAAE $n^{\circ} 71618817.6 .0000 .0053$, com parecer $\mathrm{n}^{\mathrm{o}} 2.227 .332$.

Os participantes da pesquisa foram cinco enfermeiros que atuam no $\mathrm{CC}$, as entrevistas foram coletadas por meio de entrevista semiestruturada, em uma unidade do CC de um hospital geral público, de grande porte, localizado no município de Feira de Santana, no estado da Bahia.

As entrevistas foram realizadas individualmente, em horários e locais sugeridos pelos próprios participantes e apresentaram as seguintes questões: O que você entende como conflito e dilema ético?; Como você percebe os conflitos e dilemas éticos vivenciados no gerenciamento do enfermeiro do CC?; Fale sobre um caso vivenciado de conflitos e dilemas éticos na tomada de decisão no gerenciamento do enfermeiro do CC; Quais as estratégias de enfrentamento utilizam ao vivenciarem conflitos e dilemas éticos na tomada de decisão no gerenciamento do CC?

Assim, foi apresentado o Termo de Consentimento Livre e Esclarecido (TCLE) que garantiu a plena liberdade de se recusarem a participar ou retirar seu consentimento em qualquer fase da pesquisa sem penalização alguma; além do sigilo, do anonimato e privacidade dos participantes em todas as fases da pesquisa. E a confidencialidade dos entrevistados foi assegurada mediante uso de códigos, conforme a ordem em que aconteceram as entrevistas E1, E2, E3, E4 e E5. Seguindo as orientações éticas, contidas na Resolução 466/12, do Conselho Nacional de Saúde (BRASIL, 2012).

Os dados coletados, foram analisados através do método de análise de conteúdo de Bardin que afirma que este é um "conjunto de técnicas de análise das comunicações" (BARDIN, 2016, p. 37). E como artifício suplementar à análise do conteúdo foi utilizado a Nuvem de Palavras (NP).

\section{RESULTADOS E/OU DISCUSSÃO}

Para melhor compreensão do tema em questão, foram desveladas quatro categorias e algumas subcategorias empíricas sobre o título. Assim:

A Categoria 1- Os conflitos e dilemas éticos vivenciados no $\mathrm{CC}$, que trata o requerimento da ação multiprofissional no ambiente, com pessoas de atividades e interesses distintos, apresentando duas subcategorias.

A Subcategoria I - Seguir a legislação - em que os participantes relatam a importância das ações profissionais respaldadas pela legislação, principalmente o CEPE, uma vez que este é um instrumento legal que direciona as ações éticas, relacionadas aos direitos, os deveres, as proibições e incumbências do profissional de enfermagem (DA SILVA et al., 2017). 
A Subcategoria II - Desrespeito ao profissional enfermeiro. As relações entre os profissionais que compõe a equipe que atua no cenário do $\mathrm{CC}$, ocorrem muitas vezes de forma hierarquizada e verticalizadas, desencadeando a desvalorização profissional (TRAJANO et al., 2017). Sendo apontado pelos profissionais como desencadeador de conflitos éticos na equipe

A Categoria 2- Gerenciamento do CC pelo enfermeiro, caracteriza-o como um conjunto de atividades, que entre outras ações se destacam o planejamento, organização, supervisão e avaliação de ações que tem como objetivo fornecer condições adequadas para o desenvolvimento do trabalho em equipe (SÁ MORORÓ et al., 2017). Esta, apresentou duas subcategorias.

A Subcategoria I - Estrutura física inadequada, em que os enfermeiros relatam os desafios encontrados diante da falta de recursos materiais, a insuficiência de recursos estruturais e de equipamentos, que resulta em superlotação. E Causa desgaste físico, emocional e social (JACQUES et al., 2015) nos profissionais, que reflete de forma negativa na qualidade do gerenciamento e assistência prestada.

A Subcategoria II- Falta de protocolos no CC, que os participantes relatam que a ausência de padronização faz com que os enfermeiros busquem gerenciar e tomar decisões no CC, através da sua subjetividade e conhecimentos prévios adquiridos na academia, o que favorece o surgimento de confrontos com o ambiente laboral caótico.

A Categoria 3- Tomada de decisão ao lidar com as situações vivenciadas no CC, que expõem a relevância dessa competência, diante das situações desafiadoras, relacionadas ao contexto estrutural e de relações que os enfermeiros lidam cotidianamente nesse ambiente e a necessidade de avaliar, organizar e assim decidir entre as possíveis opções, qual delas é mais adequada, segundo as evidências científicas (JENSEN; DE SOUZA GUEDES; LEITE, 2016). Em que retratou uma a Subcategoria I- Priorizando o paciente, os entrevistados relatam as dificuldades encontradas, frente a necessidade de tomar decisões priorizando o paciente que apresenta o quadro clínico mais emergente, diante do contexto de CC.

A Categoria 4- Medidas de enfrentamento às situações vivenciadas no $\mathrm{CC}$, que trata da capacidade de criar medidas para evitar e enfrentar os conflitos e dilemas que os enfermeiros lidam cotidianamente. Esta, se divide em duas classificações: A Subcategoria I- Enfermeiros buscam alternativas para evitar conflitos, em que os participantes relatam a relevância da discussão coletiva, que produz estratégias que promovem a otimização no uso do tempo e recursos, diante da escassez dos instrumentos fornecidos no ambiente (MARTINS; DALL'AGNOL, 2016).

Além da Subcategoria II - Lidando com a eclosão de conflitos, os enfermeiros relatam quais intervenções, posturas e resoluções utilizadas, frente aos conflitos e dilemas éticos vivenciados. É válido destacar que a imposição e alteração do tom de voz se destacou. Porém, o exercício da imposição, caracteriza a utilização máxima do poder da dominação, que reflete no sentimento de desvalorização profissional e ressentimentos (CIAMPONE; KURGANT, 2010). O que acarreta a falta de participação dos integrantes da equipe na tomada de decisão e ausência de apoio à gerência (AMESTOY et al., 2014).

\section{CONSIDERAÇÕES FINAIS}

A pesquisa contribuiu de forma significativa para a compreensão quanto as situações de conflitos e dilemas que são constantes no CC e se relacionam com diversos agentes causadores, justificando a assiduidade das suas ocorrências. Este, ainda permitiu observar a notoriedade existente na ambiguidade da percepção dos enfermeiros relacionada ao significado de dilema, em que na maioria das vezes foi confundido com 
conflito que delimitou o entendimento de como ele ocorre e de que forma os profissionais se comportam diante deles. Além de possibilitar a associação da interrelação existente entre as informações técnicas-científicas e a autonomia profissional.

\section{REFERENCIAS}

AMESTOY, Simone Coelho et al. Gerenciamento de conflitos: desafios vivenciados pelos enfermeiros-líderes no ambiente hospitalar. Revista Gaúcha de Enfermagem, v. 35, n. 2, p. 79-85, 2014.

ASSIS, D. S., et al. Conflitos éticos vivenciado pelo enfermeiro no centro cirúrgico frente a tomada de decisão. Convibra: gestão, educação e promoção da saúde, v.6, p. 13081-13093, 2017.

BARDIN, Laurence. Análise de conteúdo. São Paulo: Edições 70, 279 p. 2016. BRASIL, Ministério da Saúde. Diretrizes e normas regulamentadoras de pesquisas envolvendo seres humanos. Resolução 466/2012, Brasília- DF, 2012. CIAMPONE MHT, KURCGANT P. Gerenciamento de conflitos e negociação. In: KURGANT P. Gerenciamento dos serviços de enfermagem. 2 ed. Rio de Janeiro: Guanabara Koogan, 2010. p. 1-196.

Código de Ética dos Profissionais de Enfermagem. Conselho federal de Enfermagem. Brasília, 2017.

COPELLI, Fernanda Hannah da Silva et al. Gerência do cuidado e governança de enfermagem em uma maternidade: teoria fundamentada. Revista Brasileira de Enfermagem. v. 70, n. 6, 2017.

DA SILVA, Fernanda Gomes et al. A ética e a moral na assistência de enfermagem. Revista Includere, v. 3, n. 1, 2017.

JACQUES, João Paulo Belini et al. Geradores de estresse para os trabalhadores de enfermagem de centro cirúrgico. Semina: Ciências Biológicas e da Saúde, v. 36, n. 1Supl, p. 25-32, 2015.

JENSEN, Rodrigo; DE SOUZA GUEDES, Erika; LEITE, Maria Madalena Januário. Competências em informática essenciais à tomada de decisão no gerenciamento em enfermagem. Revista da Escola de Enfermagem da USP, v. 50, n. 1, p. 112-120, 2016.

MARTINS, Fabiana Zerbieri; DALL'AGNOL, Clarice Maria. Surgical center: challenges and strategies for nurses in managerial activities. Revista gaucha de enfermagem, v. 37, n. 4, 2016

OLIVEIRA, M. A. N.; SANTA ROSA, D. O. Método de Análise de Problemas Morais aplicado à prática da Enfermagem. Feira de Santana: UEFS Editora, 2014. $184 p$.

OLIVEIRA, M. A. N.; SANTA ROSA, D. O. Conflitos e dilemas éticos vivenciados pelo enfermeiro no cuidado perioperatório. Ciência, Cuidado e Saúde, v. 14, n. 2, p. 1149-1156, 2015.

OLIVEIRA, M. A. N., SANTA ROSA, D. O. Conflitos e dilemas éticos: vivências de enfermeiras no centro cirúrgico. Revista Baiana de Enfermagem. Salvador, v. 30, n. 1, p. 344-355, 2016.

SÁ MORORÓ, Deborah Dinorah de et al. Análise conceitual da gestão do cuidado em enfermagem no âmbito hospitalar. Acta Paulista de Enfermagem, v. 30, n. 3, p. 323332, 2017.

SILVA, F. G., et al. Universidade em Movimento: Educação, Diversidade e Práticas Inclusivas. A ética e a moral na assistência de enfermagem. Revista Includere, v. 3, n.1, 2017. 
TRAJANO, Maria de Fátima Cordeiro et al. Relações interpessoais no centro cirúrgico sob a ótica da enfermagem: estudo exploratório. Online braz. j. nurs.(Online), v. 16, n. 2, p. 159-169, 2017.

TREVISO, Patricia., et al. Competências do enfermeiro na gestão do cuidado. Revista de Administração em Saúde. São Paulo, v. 17, n. 69, 2017. 